\title{
Correspondence
}

\section{Oculocardiac reflex - peribulbar block or opioid-relaxant anaesthesia}

To the Editor:

The Oculocardiac reflex (OCR) can be induced by traction on the extraocular muscles. It usually manifests as bradycardia, nodal rhythm, ectopic beats, ventricular fibrillation and asystole. The reported incidence of OCR during general anaesthesia (GA) varies from $56-67 \%^{1,2}$ This study was designed to compare the effects of peribulbar block (LA) and opioid- relaxant anaesthesia on the incidence of OCR in 30 patients undergoing surgery for retinal detachment. Traction of $400 \mathrm{~g}$ was applied to all extraocular muscles using a spring balance.

Patients in group I underwent surgery using peribulbar block. In group II patients received conventional opioid-relaxant anaesthesia. Intraoperative monitoring included $\mathrm{SpO}_{2}, \mathrm{P}_{\mathrm{ET}} \mathrm{CO}_{2}$, heart rate, and arterial pressure every $5 \mathrm{~min}$. The ECG, lead II, was recorded prior to anaesthesia, and during and after traction of each extraocular muscle. OCR was considered positive if there was $10 \%$ decrease in heart rate. Analysis was with chi-square and student's $t$ test.

There was a decrease in heart rate following traction on the rectus muscles $(P<0.0005)$ and oblique muscles $(P<0.005)$ during GA (Table). The maximum change in heart rate was observed for inferior rectus. There was no decrease in heart rate, using local anaesthesia, for muscle. There were no alterations in arterial pressure under LA or GA. The incidence of dysrhythmias was $20 \%$ under GA and $6.67 \%$ under LA. These results demonstrate that the incidence of OCR during GA $(63.3 \%)$ is higher than during LA (14.4\%).

V.K. Grover MD MNAMS

N. Bhardwaj MD

N. Shobana $M D$

S.P.S. Grewal MD

Postgraduate Institute of Medical Education and Research

Chandigarh - 160012, India.

\section{REFERENCES}

1 Welbaf WR, Johnson DC. The oculocardiac reflex during extraocular muscle surgery. Arch Opthal 1965; 73: 43-5.

2 Dewar KMS, Wishart HX. The oculocardiac reflex. Proc R Soc Med 1976; 69: 373-4.

\section{Severe interactions with classic and selective monoamine oxidase inhibitors}

To the Editor:

Withholding antidepressant MAOI treatment before anaesthesia may lead to relapse but the new MAOIs are considered safe in surgical patients. ${ }^{1,2}$ We report two cases of pharmacological interactions with different MAOI drug types.

A 21 yr old, lightly depressed, woman had knee arthroscopy under spinal anaesthesia. She developed hypotension and bradycardia was treated with

TABLE Mean drop in heart rate before and during traction under local and general anaesthesia

\begin{tabular}{|c|c|c|c|c|}
\hline \multirow{3}{*}{ Muscle } & \multicolumn{2}{|c|}{ Group I } & \multicolumn{2}{|c|}{ Group II } \\
\hline & Mean HR before & Mean HR during & Mean HR before & Mean $H R$ during \\
\hline & traction $( \pm S E M)$ & traction ( \pm SEM) & traction $( \pm S E M)$ & traction $( \pm S E M)$ \\
\hline SR & $81.93(4.18)$ & $76.33(4.83)$ & $72.47(3.50)$ & $56.33(3.29)^{* *}$ \\
\hline IR & $81.67(4.28)$ & $79.47(4.39)$ & $71.60(4.12)$ & $53.60(3.03)^{* *}$ \\
\hline MR & $82.13(4.08)$ & $78.60(4.64)$ & $68.20(3.35)$ & $56.27(2.45)^{\star *}$ \\
\hline LR & $82.20(4.18)$ & $80.67(4.22)$ & $70.60(3.89)$ & $57.33(3.06)^{\star \star *}$ \\
\hline SO & $82.33(4.10)$ & $79.60(4.68)$ & $67.53(3.21)$ & $60.60(3.70)^{\star}$ \\
\hline IO & $82.27(4.36)$ & $80.87(4.71)$ & $67.00(3.69)$ & $61.53(3.63)^{\star}$ \\
\hline
\end{tabular}

SR: Superior rectus; IR: Inferior rectus; MR: Medial rectus; LR: lateral rectus; SO: Superior oblique; IO: Inferior oblique ** $P<0.0005, * P<0.005$ 
ephedrine and atropine. She developed severe headache, agitation, dyspnoea, diaphoresis, and thoracic and head blushing. Blood pressure was $245 / 125$ $\mathrm{mm} \mathrm{Hg}$ and HR 135 - $140 \mathrm{bpm}$. This changed to bradycardia and multiple, multifocal ventricular extrasystoles persisting for seconds. Midazolam, thiopentone and nitroglycerine boluses were administered: BP decreased to $185 / 105 \mathrm{~mm} \mathrm{Hg}$, and ECG showed sinus tachycardia. Ten minutes later $\mathrm{BP}$ was $130 / 75$ $\mathrm{mm} \mathrm{Hg}$, and $\mathrm{HR}$ was $110 \mathrm{bpm}$. The patient had been treated with phenelzine, $15 \mathrm{mg}$ daily for six months, which was inadvertently omitted from the history.

A 72 yr old woman with Parkinson's disease (treated with selegiline $10 \mathrm{mg}$ daily) had fixation of a neck femoral fracture, under spinal anaesthesia. She developed bradycardia and hypotension and received atropine and ephedrine. Blood pressure increased to $240 / 120 \mathrm{mmHg}$ and supraventricular tachycardia treated with urapidil and amiodarone. After $15 \mathrm{~min}$, $\mathrm{BP}$ and $\mathrm{HR}$ were normal.

Recently, reversible MAO-A inhibitors (RIMA's) and selective MAO-B inhibitors have been synthesized $^{1}$ and, although indirect or mixed agents sympathomimetic (e.g. ephedrine) are contraindicated direct agents are said to be safe.

The first patient had a typical MAOI interaction with indirect sympathomimetics and the second showed a typical non-selective MAOI interaction, although the selegiline (MAOI-B) dose was in the selective range (<

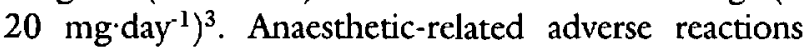
have been not described with this drug $^{3}$ and concern about MAOI interactions continues. ${ }^{4,5}$

Carlos L. Errando MD PhD

Eva Mateo MD

Dolores López-Alarcón MD

Susana Moliner MD

Hospital General Universitario de Valencia

Valencia, Spain.

\section{REFERENCES}

1 Wells DG, Bjorksten AR. Monoamine oxidase inhibitors revisited. Can J Anaesth 1989; 36: 64-74.

2 el-Ganzouri $A R$, Ivankovich $A D$, Braverman $B$, McCartby $R$. Monoamine oxidase inhibitors: should they be discontinued preoperatively? Anesth Analg 1985; 64: 592-6.

3 Kando JC, Kalunian DA. Focus on selegiline: a selective monoamide oxidase type B inhibitor. Hosp Formul 1990; 25: 849-58.

4 Clark AG. MAOIs and anaesthesia (Letter). Can J Anaesth 1996; 43: 641 .
5 Roizen MF. Monoamine oxidase inhibitors: are we condemned to relive history, or is history no longer relevant? (Editorial) J Clin Anesth 1990; 2: 293-5.

\section{Propofol administered via the carotid artery to achieve a Wada test}

To the Editor:

The unilateral injection of a short-acting barbiturate into an internal carotid artery (Wada-test) is used preoperatively to identify the dominant hemisphere in ambidextrous patients. ${ }^{1-3}$ However, amytal, amobarbitone and methohexitone are no longer available in France, hence we have tested propofol, which is not vascularly toxic, ${ }^{4}$ in this situation.

A 43-yr-old ambidextrous consenting man presented with a tumour situated in the left temporal occipital area. Lateralization of cerebral speech dominance before temporal lobectomy was desired. Transfemoral left carotid arterial catheterization was carded out under local anaesthesia. The patient was asked to keep his right upper limb elevated and to count loudly without interruption. Twenty milligrams of propofol were then injected into the left carotid artery which was followed, $13 \mathrm{sec}$ later, by complete paresis of the right upper limb and total arrest of speech for $18 \mathrm{sec}$. The EEG recordings showed slow polymorphic activity over the left fronto-temporal area of the brain. The latter decreased in intensity six minutes later. At the same time, motor and speech functions recovered. A total amnesia of the entire previous period was recorded. The patient described only the perception of an intense blue light. The fact that the patient totally broke off his speech, proved left localization of the speech site and injection into the right carotid was unnecessary.

To our knowledge, this observation is the first to describe the use of propofol to carry out a Wada-type test. The rapid psychomotor recovery and the absence of adverse events are undoubtedly an asset.

Jean E. Bazin MD, Pascale Picard MD, Jean Gabrillargues MD, Monique Dordain MD

Departments of Anaesthesia and Radiology

University Hospital

Clermont-Ferrand, France.

\section{REFERENCES}

1 Wada J, Rasmussen $T$. Intracarotid injection of sodium amytal for lateralization of cerebral speech dominance. J Neurosurg 1960; 17: 226-32.

2 Trenerry $M R$, Loring $D W$. Intracarotid amobarbital procedure. The Wada test. Neuroimaging Clin North Am 1995; 5: 721-8. 